\title{
Development of a wearable infrared shield based on a polyurethane-antimony tin oxide composite fiber
}

Sang-Mi Jeong', Jihun Ahn², Yong Kyu Choi ${ }^{3}$, Taekyung Lim', Keumyoung Seo', Taekuk Hong1', Gwang Hwi Choi', Heesoo Kim', Bo Wha Lee ${ }^{2}$, Sang Yoon Park ${ }^{3}$ and Sanghyun Ju (iD ${ }^{1}$

\begin{abstract}
Here, we investigate a wearable-based IR and thermal stealth structure that effectively blocks IR and thermal radiation from a human body or device using a polyurethane-antimony tin oxide (PU-ATO) composite fiber. The aging time of the ATO sol prepared by a sol-gel method, and the concentration of ATO with respect to that of the PU matrix were optimized to prepare PU-ATO composite fibers that simultaneously have an appropriate mechanical strength (strength of $\sim 4 \mathrm{MPa}$ and strain of $\sim 340 \%$ ) and IR- and thermal radiation-shielding properties with $\sim 98 \%$ IR light, as determined by Fourier transform IR spectroscopic studies. The fabricated PU-ATO composite fiber showed stable IRand thermal radiation-shielding properties even when exposed to ten cycles of repeated temperature changes of -20 and $+80^{\circ} \mathrm{C}$ and long-term temperature changes for 30 days. In addition, the surface of the PU-ATO composite fiber was rendered hydrophobic to prevent the distortion of the IR and thermal radiation due to the wetting of the PU-ATO composite fiber with absorbed water. The PU-ATO composite fiber-based textile proposed herein can be applied in wearable IR- and thermal radiation-shielding technologies to shield IR signals generated by objects of diverse and complex shapes.
\end{abstract}

\section{Introduction}

Stealth technology refers to a technology that renders objects unidentifiable by reducing or distorting the objects' external signals (radar, IR, acoustic, and visual signals) used to identify objects ${ }^{1-10}$. In particular, IR stealth is a technology that makes IR radiation emitted by an object as similar as possible to ambient background radiation such that an IR detection sensor fails to distinguish the target object. Although all objects with a temperature above absolute zero emit IR $(0.78-1000 \mu \mathrm{m})$, most IR signals are scattered and absorbed by

\footnotetext{
Correspondence: Sang Yoon Park (yoonpark77@snu.ac.kr) or

Sanghyun Ju (shju@kgu.ac.kr)

${ }^{1}$ Department of Physics, Kyonggi University, Suwon, Gyeonggi-do 16227,

Republic of Korea

${ }^{2}$ Department of Physics and Oxide Research Center, Hankuk University of

Foreign Studies, Yongin-si, Gyeonggi-do 17579, Republic of Korea

Full list of author information is available at the end of the article

These authors contributed equally: Sang-Mi Jeong, Jihun Ahn
}

microparticles, water vapor, or carbon dioxide molecules in the air, and only near-IR (NIR; $0.78-2.5 \mu \mathrm{m})$, mid-IR (MIR; $3-5 \mu \mathrm{m}$ ), and far-IR (FIR; $8-14 \mu \mathrm{m}$ ) signals have excellent air permeability. The wavelengths of these IR signals also overlap with the wavelength range of thermal radiation $(0.1-100 \mu \mathrm{m})$. Therefore, in accordance with the Stefan-Boltzmann law, which states that the intensity of the IR radiation is proportional to the fourth power of the object's surface temperature, IR light irradiated on an object can relay thermal energy to that object. Therefore, the most effective stealth method for avoiding IR detection and tracking is to bring the detectable IR signals of the object to a level as similar as possible to that of the ambient background radiation by reducing the surface temperature of the IR-emitting object or by an IRshielding material ${ }^{5,9,10}$. To achieve this, either the object should be wrapped with an insulating material to prevent heat from spreading to the surface of the object, or the 
intensity of the emitted IR radiation should be reduced by coating the object with a material that can shield IR signals.

Materials used in IR-shielding coatings include metal powders, conductive polymers, organic/inorganic composites, and semiconductors ${ }^{11-17}$. Metal powders have high visible and IR light reflectance owing to their low emissivity, but they inevitably suffer from a key drawback: their IR-shielding property deteriorates because of the facile oxidation of the metal under long-term exposure to air $^{13}$. In addition, because metals are heavy, they easily increase the total weight of the object to which they are applied, which is often disadvantageous. Conductive polymers and organic/inorganic composites could be shaped into various shapes/forms; as they are flexible, they can also be used as wearable materials. However, they suffer from some drawbacks: they have poor IR-shielding capabilities and mechanical properties, and the binder preparation process is also complicated ${ }^{18}$. On the other hand, semiconductors with a wide bandgap are more stable than polymers and composites in the ambient atmosphere, and have high reflectivity in the IR region. They are therefore frequently used as IR-shielding materials. Moreover, such semiconductors can also be used as wearable materials when blended with an appropriate polymer. Recently, studies on the IR-shielding properties of titanium oxide, zinc oxide, indium tin oxide, tin oxide $\left(\mathrm{SnO}_{2}\right)$, and antimony tin oxide (ATO) have been reported $^{15,19-21}$. Among these, ATO is one of the typical semiconductors with visible-light transmittance and IRshielding properties; owing to its affordable price, ATO is widely used in IR- and thermal radiation-shielding coatings. Currently, ATO nanoparticles are synthesized by a variety of techniques, such as hydrothermal, coprecipitation, combustion, sol-gel, and direct current arc plasma jet methods, and in general, the nanoparticles are mixed with a binder to form films that can be used for IR and thermal radiation shielding ${ }^{22-24}$. However, there is a lack of studies on the fabrication of ATO nanoparticles in a fiber form, instead of the typical film form, for application in wearable IR- and thermal radiation-shielding clothing. Moreover, there are reports on using a binder to coat ATO nanoparticles on a polymer-based fiber or mixing ATO nanoparticles with a polymer matrix ${ }^{25-27}$. However, when a binder is used to coat ATO nanoparticles on the fiber, the coating might be damaged under friction. When ATO nanoparticles are mixed with a polymer matrix, the mechanical properties of the fiber may degrade. Accordingly, for application in wearable IR- and thermal radiation-shielding clothing, it is necessary to develop a shielding material that can effectively increase the shielding efficiency while maintaining the mechanical strength of the fiber without significantly increasing the fiber weight.
Here, we investigated the IR- and thermal radiationshielding properties of fibers composed of a polyurethane (PU)-ATO composite. An optimal ATO sol was obtained by controlling the concentration of the ATO precursors, and aging time of the sol prepared by a sol-gel method; this sol was mixed with preset amounts of the PU solution to obtain PU-ATO composite suspensions with different compositions. A wet-spinning technique was used to fabricate PU-ATO composite fibers from composite suspensions with four different ATO concentrations. Then, the IR- and thermal radiation-shielding efficiency and mechanism of the prepared fibers were evaluated. We also determined whether the PU-ATO composite fibers could be used as a wearable material by testing their typical mechanical and optical properties according to changes in the aging time and the ATO content. Moreover, the surface of the PU-ATO composite fiber was chemically modified to render it hydrophobic, in order to resolve the problem of the distortion of the IR- and thermal radiation-shielding function when the shielding fiber is exposed to atmospheric water. Furthermore, the functional reliability of the fabricated PU-ATO composite fiber was evaluated by repeatedly testing it under applied IR and thermal radiation.

\section{Materials and methods}

\section{Fabrication of the PU-ATO composite fiber}

A $16.7 \mathrm{wt} \%$ PU solution was prepared by dissolving PU granules (Avention) in dimethylformamide (DMF, SigmaAldrich) and tetrahydrofuran (THF, Sigma-Aldrich) cosolvent (3:2 ratio). The prepared PU solution was stirred for $6 \mathrm{~h}$. An ATO sol was prepared by mixing 0.5, 1.5, 3.0 , and $4.0 \mathrm{mmol}$ of tin(II) chloride dihydrate $\left(\mathrm{SnCl}_{2} \cdot 2 \mathrm{H}_{2} \mathrm{O}\right.$, Sigma-Aldrich) and $0.05,0.15,0.3$, and $0.4 \mathrm{mmol}$ of antimony(III) chloride $\left(\mathrm{SbCl}_{3}\right.$, SigmaAldrich), respectively, in 1.4 g of DMF-THF cosolvent (3:2 ratio). Each ATO sol preparation was stirred for $6 \mathrm{~h}$ in a closed container to homogenously mix the constituents and then aged in air for 1,2 , or 3 days. The PU-ATO composite suspensions were prepared by adding one of the prepared ATO sols to $5 \mathrm{~g}$ of the PU solution. Then, the composite suspension was loaded into a $10-\mathrm{mL}$ disposable syringe installed in a syringe pump (Invisible Co.). Thereafter, the composite suspension was continuously injected into a water coagulation bath at a rate of $70 \mathrm{~mL} /$ min through an 18-gauge stainless steel syringe needle. To ensure complete removal of the solvent in the extracted PU-ATO composite fibers, the fibers were kept in the coagulation bath for $20 \mathrm{~min}$. Then, the fibers were removed from the bath and dried at room temperature $\left(20^{\circ} \mathrm{C}\right)$ for $12 \mathrm{~h}$. After drying, the PU-ATO composite fibers were immersed in a $5 \mathrm{mM}$ solution of HDF-PA (Apollo Scientific) in isopropyl alcohol (JT Baker) for $30 \mathrm{~min}$. Then, the PU-ATO composite fiber with HDP-PA 


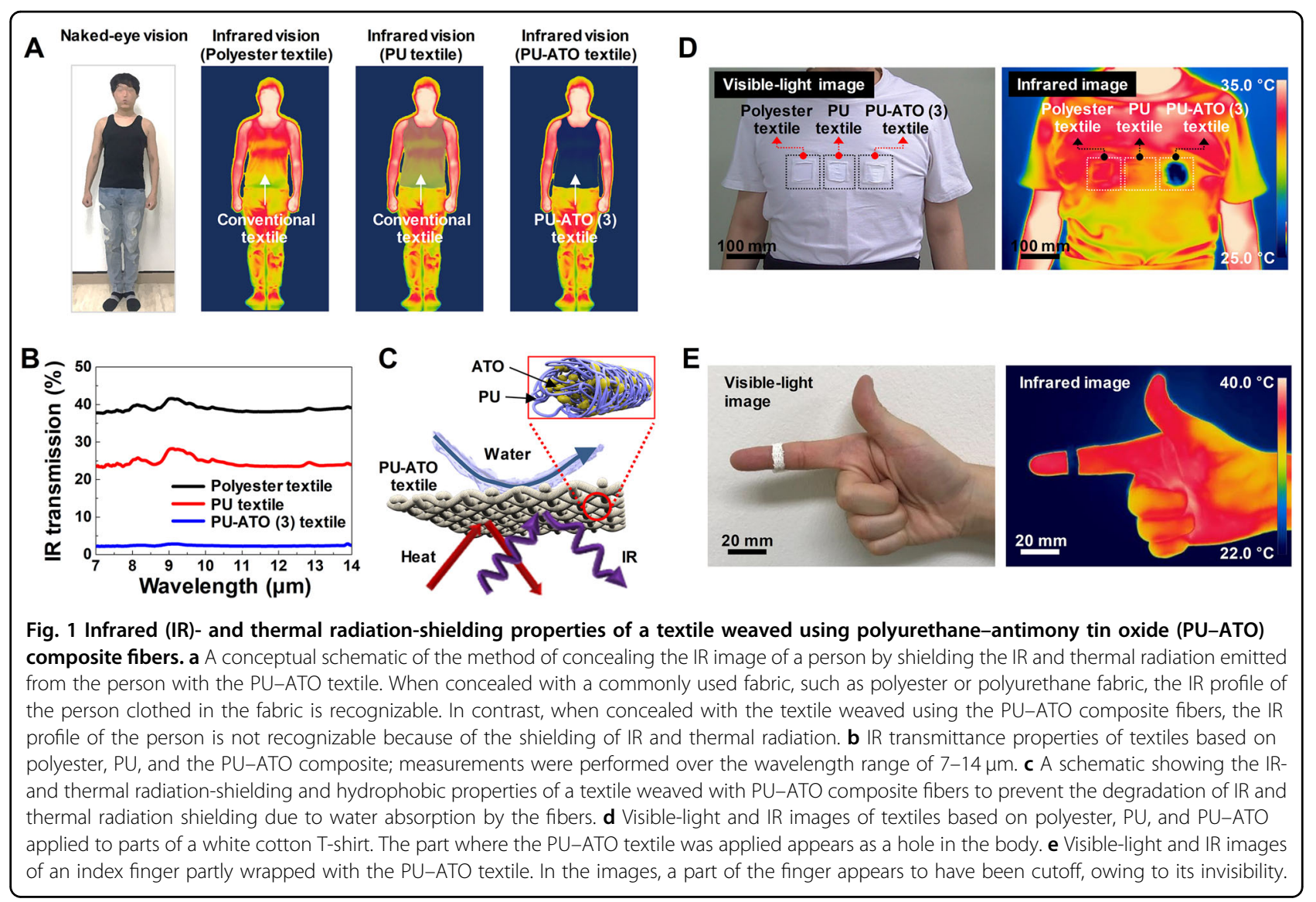

was dried at room temperature $\left(20^{\circ} \mathrm{C}\right)$ for $6 \mathrm{~h}$. Finally, the dried PU-ATO composite fiber was thermally annealed for $1 \mathrm{~h}$ at $150^{\circ} \mathrm{C}$ using a forced convection drying oven (OF-02GW, Jeio Tech).

\section{Analysis of the optical, electrical, and mechanical properties of the PU-ATO composite fiber}

The average size of the ATO sol synthesized by the sol-gel method was analyzed by DLS (Nanotrac Wave, Microtrac), while its crystallinity was analyzed by XRD. Light transmission in the NIR region was analyzed using a UV-vis-NIR spectrophotometer (LUX-2000, Invisible Co.). The surface morphology and size of the PU-ATO composite fibers were characterized by FE-SEM (S-4800, Hitachi), while chemical mapping for the identification of the constituents of the fiber was carried out by EDS (7593-H, Horiba). The surface morphology and elemental distribution of the PU-ATO composite fiber were analyzed by AFM. The water wettability of the composite fibers was assessed using a contact angle analyzer (Phoenix 300, SEO Co.). Thermogravimetric analysis (TGA/DSC 1, Mettler Toledo) of the PU-ATO composite fibers was performed under a nitrogen atmosphere. Mechanical properties, such as the tensile strength and strain, were evaluated at room temperature using a TMA
(TMA7100, Hitachi). IR transmission was analyzed using an ATR-FTIR spectrometer (Tensor 27 Spectrometer, Bruker). A hot plate (MSH-20D, DAIHAN Scientific) was used as the heating source, and a Peltier module was used as the cooling source. The IR- and thermal radiationshielding properties of the textiles were analyzed by imaging using a thermal IR camera (T-420, FLIR) after placing the textiles $2 \mathrm{~mm}$ from the heating and cooling source.

\section{Results and discussion}

According to Wien's displacement law $\left(\lambda_{m}=2897.8 / T\right)$, if an object is assumed to be a black body, the maximum wavelength of the radiation $\left(\lambda_{m}\right)$ of the object at room temperature (near $20^{\circ} \mathrm{C}$ ) is $\sim 9.9 \mu \mathrm{m}$, which is located in the FIR region, whereas an object at $1000^{\circ} \mathrm{C}$ emits $\sim 2.3-\mu \mathrm{m}$ NIR light. Therefore, to render an object indistinguishable by the IR detector sensor, it is important to make the IR and thermal radiation intensity of the object being detected as similar as possible to the IR and thermal radiation intensity of the surrounding environment and objects. Figure 1a shows a conceptual schematic of a person emitting IR and thermal radiation, as viewed with visible-light and IR cameras. When the person is viewed with an IR camera, he/she appears colorful due to the 
differences in the temperatures of different parts of the body. Even when the person wears typical clothing, such as polyester or PU fabric, the IR and thermal radiation emitted from the human body passes through the fabric and becomes visible. In contrast, when a part of the human body is concealed with PU-ATO composite fiberbased clothing with IR- and thermal radiation-shielding properties, the IR and thermal radiation emitted from the human body is shielded, and the person merges with the background; accordingly, the IR camera cannot recognize the person. The PU-ATO composite fiber-based textile (PU-ATO textile) developed in the present study has superior IR- and thermal radiation-shielding properties compared with those of regular fabrics, such as polyester or PU fabric. For the fabrication of the PU-ATO composite fiber, a PU-ATO composite suspension was prepared by evenly embedding an ATO sol in a PU matrix that has elongation ability, tensile strength, and a high modulus favorable for forming a fiber; then, fibers were obtained by wet-spinning the composite suspension. The PU-ATO (3) composite fibers used to make the IR- and thermal radiation-shielding textiles were fabricated under optimal conditions, as determined by the assessment of their mechanical, chemical, and optical properties.

The attenuated total reflection-Fourier transform infrared (ATR-FTIR) spectra in Fig. 1b reveal that the IR transmittance of textiles made with polyester, $\mathrm{PU}$, and PU-ATO (3) are $~ 40,25$, and $2 \%$, respectively. Note that the ATR-FTIR spectroscopy was performed in the wavelength range of $7-14 \mu \mathrm{m}$, which includes the entire wavelength range of $7.5-13 \mu \mathrm{m}$ detected by a thermal IR camera. The low IR transmittance of the PU-ATO (3) textile is due to the uniform dispersion of the ATO sol in the PU matrix of the fiber. In general, $\mathrm{SnO}_{2}$, a typical ntype semiconductor with a large bandgap $\left(E_{\mathrm{g}}=3.6 \mathrm{eV}\right.$ at $300 \mathrm{~K}$ ), is doped with a specific element, such as indium, niobium, tantalum, or antimony (Sb), depending on the purpose of application. In particular, ATO, which is Sbdoped $\mathrm{SnO}_{2}$, is a typical semiconductor with visible-light transmittance and IR- and thermal radiation-shielding properties, and its optical and electrical properties can be modulated by controlling the Sb dopant concentration, particle size, and crystallinity ${ }^{21,28}$. The excellent IR- and thermal radiation-shielding effect of ATO arises from the localized surface plasmon resonance generated by the $\mathrm{Sb}$ doping effect. Here, a plasmon refers to a quasiparticle with collective oscillations of free electrons in a conductor, such as a metal. In general, plasmons are present only on the surface of nanoparticles, and accordingly, they are also referred to as surface plasmons. When IR light is irradiated on a metal nanoparticle, the light energy is altered by the surface plasmons and accumulates on the surface of the nanoparticle. Such interaction of light with nanoparticles is referred to as surface plasmon resonance.
Plasmons generated by the collective oscillation of free electrons have a very important effect on the optical properties of the material. For example, light with a frequency lower than the plasmon frequency is reflected by the oscillating free electrons in the conduction band, whereas light with a frequency higher than the plasmon frequency is transmitted. In other words, the frequency at which IR radiation can be reflected by plasmon vibration is proportional to the plasmon frequency $\left(\omega_{p}\right)$ in accordance with Eq. (1):

$$
\omega_{s p}^{2}=\frac{\omega_{p}^{2}}{1+\varepsilon_{m}}
$$

where $\omega_{s p}$ is the surface plasmon frequency, and $\varepsilon_{m}$ is the dielectric constant of the surrounding medium. The plasmon frequency $\left(\omega_{p}\right)$ is proportional to the square root of the free electron density $(N)$ (Eq. (2)):

$$
\omega_{p}=\sqrt{\frac{N e^{2}}{m_{e} \varepsilon_{\infty} \varepsilon_{0}}}
$$

where $e$ is the electron charge, $m_{e}$ is the effective mass of an electron, $\varepsilon_{0}$ is the vacuum permittivity, and $\varepsilon_{\infty}$ is the optical dielectric constant ${ }^{21}$. Sb may exist in two different oxidation states in a solid solution of $\mathrm{SnO}_{2}$. Furthermore, the ionic radius of $\mathrm{Sn}^{4+}(0.83 \AA)$ is slightly larger than that of $\mathrm{Sb}^{5+}(0.74 \AA)$ and slightly smaller than that of $\mathrm{Sb}^{3+}$ $(0.93 \AA)^{29}$. At a low doping level, the n-type dopant $\mathrm{Sb}^{5+}$ is dominant, whereas the p-type dopant $\mathrm{Sb}^{3+}$ is dominant at a high doping level. The doping level at which $\mathrm{Sb}^{5+}$ transforms to $\mathrm{Sb}^{3+}$ is known to be $\sim 15 \%{ }^{30-32}$. According to Eq. (2), ATO, which is $\mathrm{SnO}_{2}$ doped with n-type dopant $\mathrm{Sb}^{5+}$, has an increased free electron density $(N)$ compared with undoped $\mathrm{SnO}_{2}$, and its plasmon frequency $\left(\omega_{p}\right)$ is also increased. Moreover, radiation with a frequency lower than the electron plasmon frequency $\left(\omega_{p}\right)$ is completely reflected without passing through the material. Therefore, the IR reflectivity ratio increases because of free electrons generated by $\mathrm{Sb}^{5+}$ ions in ATO. By employing the PU-ATO composite fiber-based textile with ATO sol evenly embedded in the PU matrix, the IR radiation emitted by an object could be effectively reflected. As shown by the inset image in Fig. 1c, the flexible PU-ATO composite weaved into a textile has a mesh structure, which is more advantageous than a more densely weaved conventional polyester or PU textile in terms of IR- and thermal radiation-shielding properties, as well as air permeability. In addition, because the hydrophilic surface of the ATO sol generated by the sol-gel reaction can be chemically modified to render it hydrophobic, IR distortion that can occur when the textile becomes wet can be prevented. The flexibility, mesh structure, and hydrophobicity of the PU-ATO composite 
textile demonstrate that it is suitable for use as a wearable IR shield.

To increase the IR-shielding rate of the PU-ATO composite fiber, the ATO sol content in the PU matrix of the fiber was increased. As the content of the ATO constituting the PU-ATO composite solution increases, the amount of ATO sol exposed to the surface during thinfilm formation increases, and the IR transmittance of the PU-ATO composite solution decreases according to the plasmon reflection properties of the ATO. Furthermore, to enhance the IR-shielding rate of the PU-ATO composite fiber, the crystallinity of the ATO was increased by increasing the aging time of the ATO sol. By increasing the crystallinity of the ATO sol, the semiconducting properties are further expressed, and the plasmon reflection effect can be increased by the collective vibration of free electrons ${ }^{33}$.

To confirm the IR- and thermal radiation-shielding effect, a part of the human body was concealed with the PU-ATO (3) composite textile, and the IR and thermal radiation emitted by the human body was captured with the IR camera. The image shown on the left side of Fig. 1d is a visible-light image of a person wearing a white cotton T-shirt partially stitched with polyester, PU, and PU-ATO (3) composite-based textiles. The size of each textile is $\sim 50 \times 50 \mathrm{~mm}^{2}$. The image shown on the right side of Fig. 1d is the IR image of the same person wearing the $t$-shirt. The image shows the appearance of various IR intensities throughout the entire T-shirt that result from the body heat from the person. Among the three areas where the textiles (polyester, PU, and PU-ATO (3)) were applied, the area where the PU-ATO (3) textile was applied shows a low IR intensity, appearing as if there is a hole in the chest. Note that when measured with the IR camera, the temperature in the chest area was found to be $\sim 31-35^{\circ} \mathrm{C}$, whereas the temperatures measured from the area in which the three fabrics were applied were $\sim 33^{\circ} \mathrm{C}$ (polyester), $\sim 28^{\circ} \mathrm{C}$ (PU), and $\sim 24^{\circ} \mathrm{C}$ (PU-ATO (3)). The ambient temperature around the person was $\sim 26^{\circ} \mathrm{C}$, which is comparable with the temperature measured from the PU-ATO (3) composite fiber-based textile. Based on these findings, it was confirmed that the PU-ATO (3) composite fiber-based textile could effectively shield IR and thermal radiation generated by the human body. The image shown on the left side of Fig. 1e is a visible-light image of an index finger with the middle part wrapped with the PU-ATO (3) composite fiber-based textile. The width and length of the white PU-ATO (3) textile wrapped around the index finger are $\sim 6$ and $\sim 15 \mathrm{~mm}$, respectively. The image shown on the right side of Fig. 1e is the IR image of the hand with the PU-ATO (3) textile wrapped around the index finger. In contrast to the handemitting IR with varying intensities due to body heat, the part wrapped with the PU-ATO (3) textile shows an IR intensity that is comparable with that of the surrounding background; it appears as if a part of the finger has been cutoff. Note that the temperature of the finger measured with the IR camera was $\sim 37^{\circ} \mathrm{C}$, whereas the temperature in the area where the PU-ATO (3) textile was applied was $\sim 22^{\circ} \mathrm{C}$; the ambient temperature around the hand was $\sim 21^{\circ} \mathrm{C}$. These findings confirm that the PU-ATO (3) textile exhibits excellent properties with regard to its functionality as an IR and thermal radiation shield.

The IR-shielding studies reported thus far used a method of mixing a solid metal or oxide nanoparticle with a binding material to fiberize or coat the outside of the raw fiber ${ }^{34-38}$. Conversely, this study used composite materials uniformly embedded with ATO, i.e., IRshielding materials, inside the polymer. To our knowledge, this is the first study to use composite materials in which sol-gel ATO sol particles with high surface interfacial forces are uniformly embedded in a flexible polymer. As the concentration and aging time of the ATO sol increase, the crystallinity of the ATO increases, thus enhancing the IR shielding rate.

Figure 2a shows the schematic of the method used to prepare PU-ATO composite suspensions by mixing an equal amount of the PU solution with an ATO sol solution, which was prepared with different ATO precursor concentrations and aged for different durations. The size and crystallinity of ATO sol particles prepared by a sol-gel method can be altered by controlling the ATO precursor concentration and aging time, even under mild processing conditions $\left(20^{\circ} \mathrm{C}, 1 \mathrm{~atm}\right)$. Moreover, unlike in the case of mixing nanoparticles with a polymer matrix, the ATO sols can be incorporated into the PU matrix because of the hydrogen bonding interactions between the reactive functions on the ATO sol surface and hydrophilic PU polymer chains. Accordingly, there is no significant degradation in the mechanical properties of the polymer after fabrication of the composite fiber. In this study, to synthesize the ATO sol $\left(\mathrm{SnO}_{2}\right.$ sol doped with $\left.10 \% \mathrm{Sb}\right)$, the host precursor tin(II) chloride dehydrate $\left(\mathrm{SnCl}_{2} \cdot 2 \mathrm{H}_{2} \mathrm{O}\right)$ and the dopant precursor $\mathrm{SbCl}_{3}$ were mixed at a molar ratio of 10:1 with DMF/THF cosolvent (DMF:THF, 3:2). The $\mathrm{SnO}_{2}$ sol doped with 10\% Sb used in this study is $\mathrm{SnO}_{2}$ doped with $\mathrm{Sb}^{5+}$ at a low doping level, and the IR reflectivity ratio is higher than that of undoped $\mathrm{SnO}_{2}$ because of free electrons generated by $\mathrm{Sb}^{5+}$ ions ${ }^{21,30}$. Here, four different ATO precursor concentrations $(0.5,1.5,3.0$, and $4.0 \mathrm{mmol})$ and four different aging times (not aged and aged for 1, 2, and 3 days) were used to synthesize the ATO sols with controlled sol particle size and crystallinity. Note that ATO sols prepared by mixing $1.4 \mathrm{~g}$ of DMF/THF cosolvent (3:2 ratio) with $0.5,1.5,3.0$, and $4.0 \mathrm{mmol}$ of ATO precursor $(0.5,1.5,3.0$, and $4.0 \mathrm{mmol}$ of $\mathrm{SnCl}_{2} \cdot 2 \mathrm{H}_{2} \mathrm{O}$ with $0.05,0.15,0.3$, and $0.4 \mathrm{mmol}$ of $\mathrm{SbCl}_{3}$, respectively) are referred to as ATO (1), ATO (2), ATO (3), and ATO (4). As shown, ATO sols 

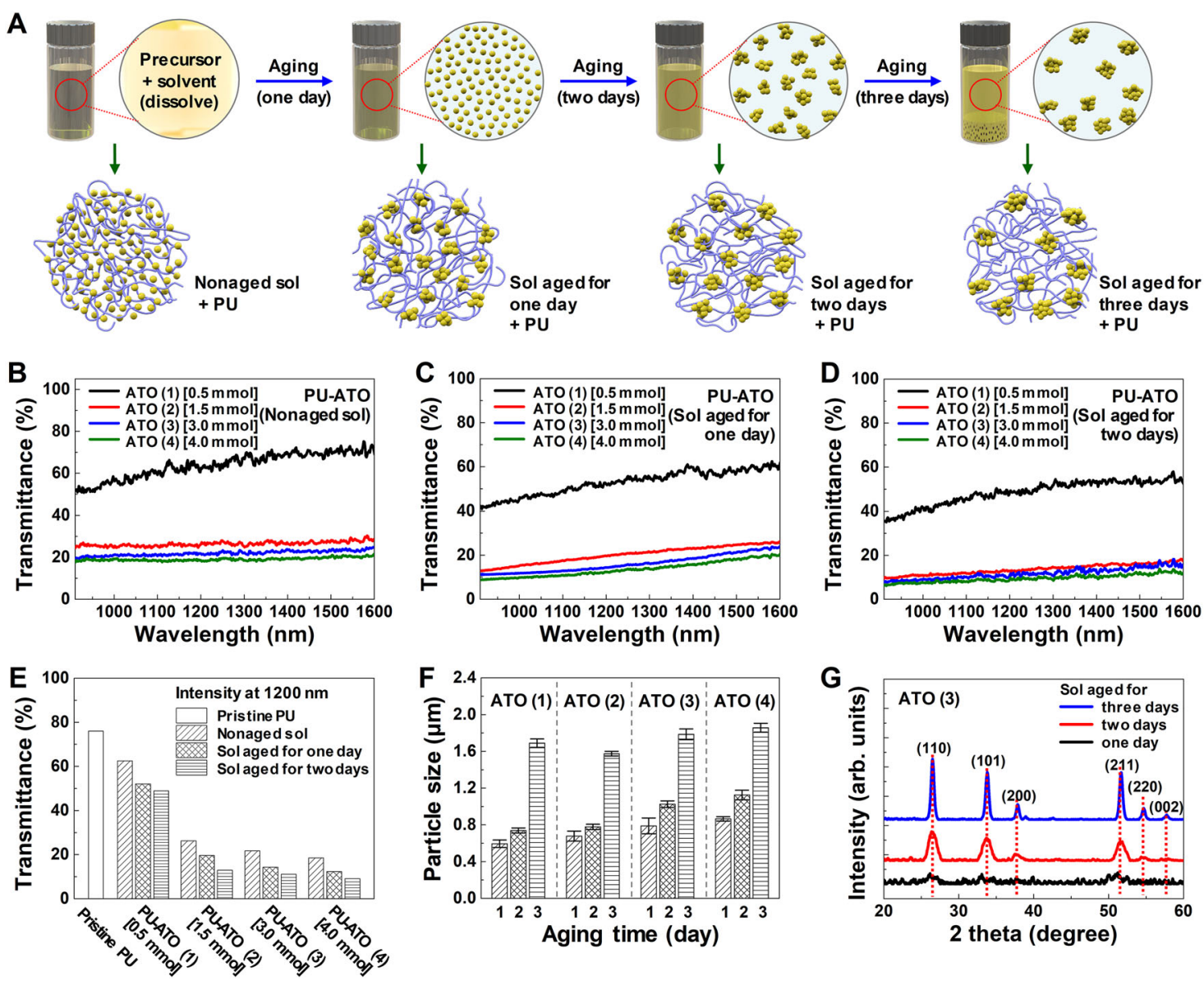

Fig. 2 Schematic of the preparation of the ATO sol and PU-ATO composite suspensions and IR transmittance and crystallinity of PU-ATO composite thin films. a Preparation of the ATO sol and PU-ATO composite suspensions by changing the ATO concentration and aging time. IR transmittance of thin films formed with PU-ATO composite suspensions according to four different ATO sol concentrations and four different aging times. b ATO precursors were mixed with an equal amount of the PU solution without aging the ATO sol, c ATO sol was aged for 1 day and mixed with an equal amount of the PU solution, and $\mathbf{d}$ ATO sol was aged for 2 days and mixed with an equal amount of the PU solution. $\mathbf{e}$ Change in the IR transmittance of PU-ATO composite thin films according to changes in the ATO concentration and sol aging time. $\mathbf{f}$ Change in the average size of sol particles according to the ATO concentration and aging time, as determined by dynamic light scattering (DLS). $\mathbf{g}$ X-ray diffraction (XRD) patterns showing the change in the crystallinity of sol particles according to the aging time.

with different ATO concentrations aged for different durations were mixed with the same amount $(5 \mathrm{~g})$ of a $16.7 \mathrm{wt} \%$ PU solution in the DMF-THF cosolvent (3:2 ratio), and stirred evenly for at least $6 \mathrm{~h}$ to prepare the PU-ATO composite suspensions. To verify the optical properties of the prepared PU-ATO composite suspensions with different compositions, their transmittance in the NIR range was evaluated by ultraviolet-visible-nearinfrared (UV-vis-NIR) spectroscopy.

Figure $2 \mathrm{~b}$ shows the transmittance in the NIR region of thin films fabricated using the PU-ATO composite suspensions (not sol aged) prepared by directly mixing the ATO precursors with the PU polymer. Note that the PU-ATO composite thin film was solidified by immersion in a water bath for $20 \mathrm{~min}$, similar to when fabricating the fiber by wet-spinning; the thickness of the fabricated thin film was $\sim 120 \mu \mathrm{m}$. Here, the ATO sols were prepared without aging, and only the concentration of ATO mixed with the PU polymer was changed. While the PU-ATO composite suspensions were mixed for at least $6 \mathrm{~h}$, the ATO precursors in the PU matrix underwent hydrolysis and condensation reactions to form ATO sol particles. As shown in Fig. 2b, the FTIR results indicate that the IR transmittance tends to decrease rapidly with an increase in the concentration of ATO and then gradually saturates. This is because the amount of the ATO sol exposed on the film's surface during thin-film formation increases with increasing ATO content in the composite suspension; the IR transmittance of the PU-ATO composite thin film decreases according to the ATO plasmon reflection properties (Supplementary Figs. S1, S2, Supplementary Information). Figure 2c, d shows 
the IR transmittance of thin films fabricated by aging ATO sols of different concentrations for 1 or 2 days at room temperature $\left(20^{\circ} \mathrm{C}\right)$, without stirring and then mixing each of them with the PU solution. As shown in the figures, the tendency of a rapid decrease followed by gradual saturation of the IR transmittance with increasing ATO concentration is observed, regardless of the aging time for all PU-ATO composite films. However, Fig. 2e, which compares the IR transmittance of different thin films at a wavelength of $1,200 \mathrm{~nm}$ (data extracted from Fig. $2 b-d)$, clearly reveals a gradual decrease in the IR transmittance with an increase in the aging time. On the other hand, when the IR transmittances of thin films with ATO sols aged for 2 and 3 days were compared, no distinct difference was observed (Supplementary Fig. S3, Supplementary Information).

Dynamic light scattering (DLS) was used to identify the average size of ATO sol particles according to the aging time. As shown in Fig. 2f, the size of ATO sol particles increased with increases in the ATO concentration and aging time. These results are consistent with the IR transmittance being inversely proportional to the ATO concentration, as shown in Fig. 2b-e. Moreover, as shown in Fig. $2 \mathrm{~g}$, the diffraction peaks of ATO sol particles appeared at (110), (101), (200), (211), (220), and (002) when $3 \mathrm{mmol}$ of the ATO sol (referred to as ATO (3)) was aged between 1 and 3 days. The peaks are very similar to the diffraction peaks of $\mathrm{SnO}_{2}{ }^{39}$, indicating that $\mathrm{Sb}$ was doped well in the lattice of $\mathrm{SnO}_{2}$ in the ATO sol. Moreover, each diffraction peak became sharper and more intense with an increase in the aging time from 1 to 3 days, suggesting that the crystallinity of ATO sol particles increased as the aging time increased. In general, during aging, sol particles grow in size as they randomly collide with each other. Cohesion between sol particles occurs through forces such as van der Waals forces between particles; if the aging time is too long, the primary particles grow into significantly larger particles and eventually sediment under the influence of gravity ${ }^{40}$. As shown in Fig. 2f, the particles grew to a size larger than $1.5 \mu \mathrm{m}$ by the third day, and some amount of the precipitate settled at the bottom of the container. When precipitates are present, the dispersion of the composite in the solvent is decreased, which could degrade the mechanical properties of the fabricated polymer composite fiber.

As the aging time of the ATO sol increased, the strain and strength of the fabricated PU-ATO composite fiber, which represent its mechanical properties, tended to decrease (Supplementary Fig. S4, Supplementary Information). This is because the size of the ATO sol particles increased as the aging time increased, and their interactions with polymer chains decreased partially as a consequence. In particular, the stability of the dispersion of the composite in the solvent decreased starting from an aging time of 3 days because of the precipitation of ATO sol particles. As a result, the strain and strength of the fabricated PU-ATO composite fiber decreased rapidly. Here, the composite dispersion in DMF/THF showed no precipitation when aged for 2 days, implying that there would be almost no degradation in the mechanical properties. Therefore, the samples aged for 2 days, which showed the best IR- and thermal radiation-shielding properties, were selected for the fabrication of the IR- and thermal radiation-shielding fiber and textile. Using PU-ATO composite suspensions prepared from ATO sols of four different concentrations $(0.5,1.5,3.0$, and $4.0 \mathrm{mmol}$ ) aged for 2 days, PU-ATO composite fibers were fabricated by a conventional wet-spinning method. The four types of PU-ATO composite suspensions were injected into a coagulation bath containing water through a syringe. Here, to fabricate the fiber by wet-spinning, it is important that the coagulation liquid be a nonsolvent for PU and ATO while being miscible with THF and DMF. Therefore, deionized (DI) water was used as the coagulation liquid. When the PU-ATO composite suspension in the fiber form is injected into DI water via a syringe, the concentration difference causes an exchange between the coagulation liquid (DI water) and the solvent of the composite (THF and DMF). As DI water penetrates the PU-ATO composite fiber, the solubility of the PU and ATO is gradually reduced, causing the solidification of the PU-ATO composite into a composite fiber. PU-ATO composite fibers fabricated in this manner have evenly embedded ATO sol particles in the PU matrix; additionally, because of the localized surface plasmon resonance of such ATO sol particles, the PU-ATO composite fibers reflect the IR light irradiated from the outside. When the PU-ATO composite thin films were annealed for $1 \mathrm{~h}$ at four different temperatures $\left(25,100,150\right.$, and $\left.200^{\circ} \mathrm{C}\right)$, the IR transmission tended to decrease with an increase in the temperature (Supplementary Fig. S5A, Supplementary Information). Although the films annealed at 25 and $200^{\circ} \mathrm{C}$ did not show a significant change in transmission (with up to only $\sim 10 \%$ difference), the IR transmission of the composite fiber could be reduced further by a simple thermal annealing process. Accordingly, the fabricated composite fibers were thermally annealed for $1 \mathrm{~h}$ at four different temperatures $\left(25,100,150\right.$, and $\left.200^{\circ} \mathrm{C}\right)$. However, the degradation of the PU-ATO composite fiber began at $200^{\circ} \mathrm{C}$ (Figure S5B, Supplementary Information). It is believed that although heat treatment at a high temperature $\left(\geq 500^{\circ} \mathrm{C}\right)$, where sintering of ATO sol occurs, cannot be applied because of the degradation of the organic PU matrix, an increase in the annealing temperature up to $150^{\circ} \mathrm{C}$ facilitated condensation of the unreacted precursor molecules present inside the ATO sol particles, causing an increase in its crystallinity ${ }^{41}$. 

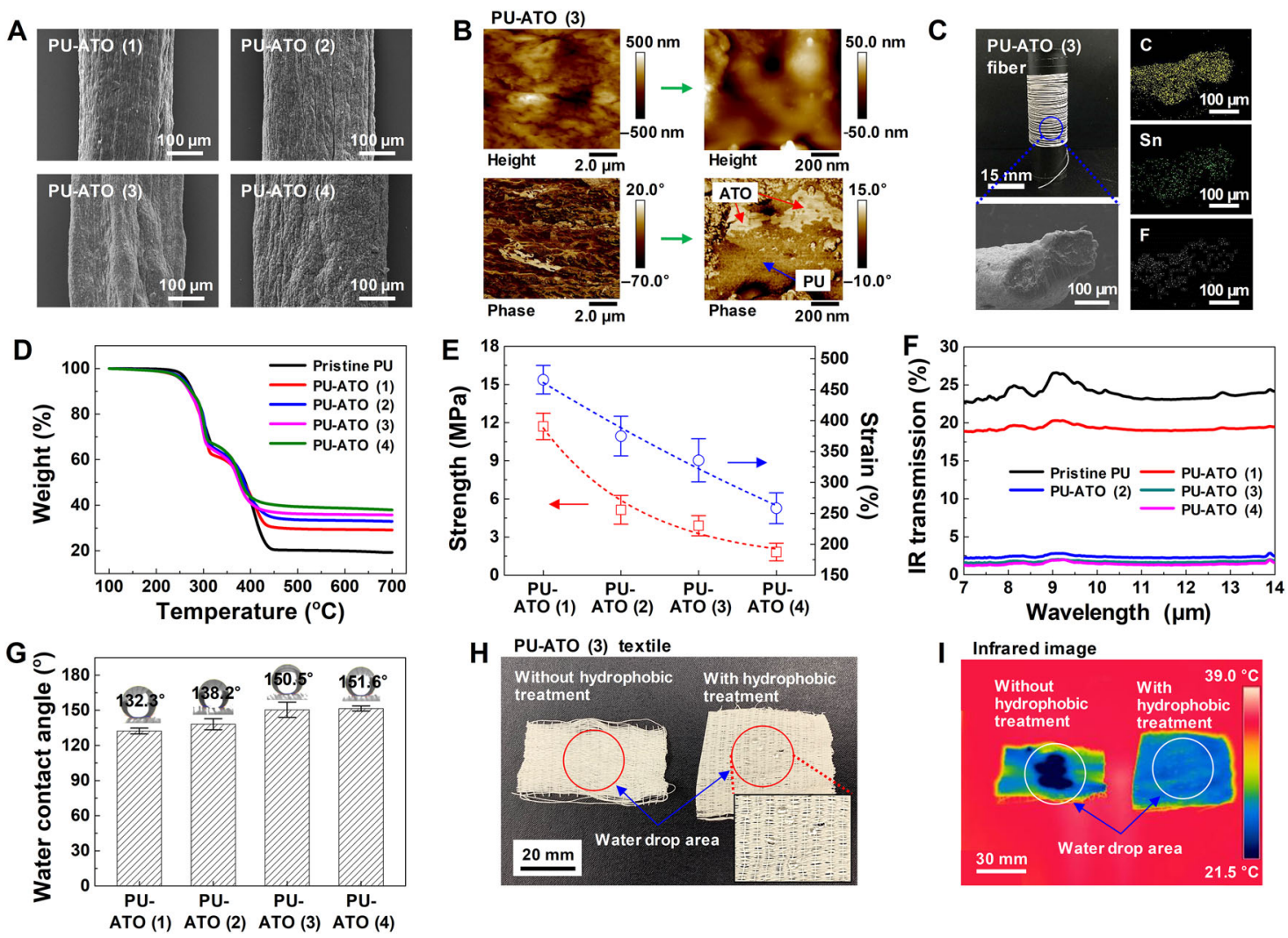

Fig. 3 Surface structure, material composition, thermal stability, strength, IR transmission, and hydrophobic properties of PU-ATO composite fibers. a FE-SEM images of PU-ATO (1-4) composite fibers with four different ATO concentrations. $\mathbf{b}$ Height and phase-mode AFM images of a PU-ATO (3) composite fiber. c Optical image of a PU-ATO (3) composite fiber wrapped around a plastic rod with a diameter of $17 \mathrm{~mm}$ and cross-sectional FE-SEM image of the fiber. EDS elemental maps showing the distribution of carbon, tin, and fluorine in the fiber. $\mathbf{d}$ TGA, e TMA, $\mathbf{f} \mid R$ transmission between 7 and $14 \mu \mathrm{m}$, and $\mathbf{g}$ water contact angles of PU-ATO (1-4) composite fibers. $\mathbf{h}$ Photograph of water droplets dropped on top of pristine and hydrophobic PU-ATO (3) composite fiber-based textiles. $\mathbf{i}$ IR images of pristine PU-ATO (3) composite fiber-based textile partially wetted by water and hydrophobic-treated PU-ATO (3) composite fiber-based textile not wetted by water when heated on a hot plate at $40{ }^{\circ} \mathrm{C}$ for $1 \mathrm{~min}$.

Based on these findings, the fabricated PU-ATO composite fibers were thermally annealed at $150^{\circ} \mathrm{C}$ for $1 \mathrm{~h}$ to maximize their IR- and thermal radiation-shielding properties.

As shown in the FE-SEM images in Fig. 3a, the diameters of the PU-ATO $(1,2,3$, and 4) composite fibers increased slightly as the ATO content increased: $\sim 260$ (PU-ATO (1)), 300 (PU-ATO (2)), 330 (PU-ATO (3)), and $\sim 370 \mu \mathrm{m}$ (PU-ATO (4)). This is because as the ATO content increases, the PU content in the fabricated PU-ATO composite fiber decreases. Accordingly, as the PU content decreases, alignment and shrinkage of the PU polymer chains occur to a lesser degree during the drying of fibers after wet-spinning, which causes the diameter of the fiber to increase slightly.

Figure $3 \mathrm{~b}$ displays the atomic force microscopic (AFM) images showing the surface characteristics of the PU-ATO (3) composite fibers. The height mode AFM image of the PU-ATO (3) composite fiber shows its surface morphology with height variation within $1 \mu \mathrm{m}$. Moreover, the area of the ATO sol embedded in the PU matrix was identified by the phase-mode AFM image. In the phase-mode AFM image, the difference between high and low contrast indicates phase shifts in that area. The morphology of the imaged area is irregular, and the area accounts for particles of dozens of nanometers to $500 \mathrm{~nm}$ size on the surface of the PU-ATO (3) composite fiber, which is less than the size of the ATO sol particle $(\sim 1 \mu \mathrm{m})$. In the phase image of the PU-ATO (3) composite fiber, the area consisting of ATO with relatively high contrast is distributed locally inside the PU matrix with low contrast.

Figure 3c shows an optical image of a PU-ATO (3) composite fiber wrapped around a plastic rod and energydispersive X-ray spectroscopy (EDS) element maps of the fiber cross-section. Here, to make the PU-ATO (3) composite fiber hydrophobic, the fiber was coated with a hydrophobic layer by immersing it in a $(1 \mathrm{H}, 1 \mathrm{H}, 2 \mathrm{H}$, 
2H-heptadecafluorodec-1-yl)-phosphonic acid (HDF-PA) solution in isopropyl alcohol (IPA). During this process, self-assembled monolayers (SAMs) with strong chemical bonds are formed due to the condensation reaction between the phosphonic acid groups of HDF-PA molecules and hydroxyl groups on the surface of the ATO sol particle, which is a metal oxide ${ }^{42}$. As seen in the EDS maps, carbon as the main component of PU, tin in ATO, and fluorine in the HDF-PA SAMs are evenly distributed in the PU-ATO (3) composite fiber.

Figure $3 \mathrm{~d}$ shows the thermogravimetric analysis (TGA) curves of the PU-ATO composite fibers with four different ATO concentrations. The temperature range of TGA is $100-700^{\circ} \mathrm{C}$. The thermograms show section I between $\sim 250^{\circ} \mathrm{C}$ and $300^{\circ} \mathrm{C}$, where a sharp weight loss occurred, and section II between $300^{\circ} \mathrm{C}$ and $400{ }^{\circ} \mathrm{C}$, where a gradual weight loss occurred. In general, the PU polymer includes hard and soft segments. In section I, breakage of urethane bonding due to the pyrolysis of hard segments occurred. In section II, polyol decomposition due to the pyrolysis of soft segments occurred ${ }^{43}$. At temperatures greater than $450^{\circ} \mathrm{C}$, only the inorganic highmelting ATO remains after the degradation of the polymer chains, and as a result, no further weight loss occurred. Consequently, the final remaining mass at the reference temperature of $700^{\circ} \mathrm{C}$ in the TGA thermograms of the PU-ATO composite fiber tends to increase according to the ATO content from 19\% (pristine PU) to 29\% (PU-ATO (1)), 33\% (PU-ATO (2)), 36\% (PU-ATO (3)), and 38\% (PU-ATO (4)).

To apply the fabricated composite fiber as a wearable textile, its mechanical properties must be verified. Figure $3 \mathrm{e}$ shows the tensile strength (maximum load) and strain (elongation) values at the breaking point of the PU-ATO composite fibers during the tensile test conducted using a thermomechanical analyzer (TMA). As the ATO content increased, both the tensile strength, 11.70 (PU-ATO (1)), 5.14 (PU-ATO (2)), 3.90 (PU-ATO (3)), and 1.82 (PU-ATO (4)) MPa, and the tensile strain, 466.0 (PU-ATO (1)), 374.9 (PU-ATO (2)), 335.7 (PU-ATO (3)), and 258.3\% (PU-ATO 4), of the fiber showed gradually decreasing trends. Consequently, as the ATO content increased, the interactions between the PU polymer chains became weaker, which caused a decline in the mechanical properties of the PU-ATO composite fiber because of the decreased crystallinity of the PU polymer matrix ${ }^{44}$. The tensile strength of $\sim 2-12 \mathrm{MPa}$ and strain of $\sim 250-470 \%$ for the PU-ATO (3) composite fiber are similar to those of the polyester- or PU-based fibers fabricated by conventional wet-, electro-, and melt-spinning methods (strength: 23-250 MPa, strain: 11-330\% for polyester, and strength: 6-60 MPa, strain: $\sim 120-750 \%$ for PU) ${ }^{4-46}$.

Figure $3 \mathrm{f}$ shows the IR transmission in the IR region (wavelength range, $7-14 \mu \mathrm{m}$ ) of the pristine PU fiber and
PU-ATO composite fibers with four different ATO concentrations, as measured by ATR-FTIR. The pristine PU fiber showed an IR transmission of $~ 25 \%$; however, as the concentration of ATO with high IR reflectance increased, the IR transmission of the PU-ATO composite fiber tended to decrease. In particular, the PU-ATO (1) composite fiber showed an IR transmission of $\sim 20 \%$, whereas a very low IR transmission of $\leq 3 \%$ was found for the PU-ATO (2) composite fiber and other specimens. Therefore, for the subsequent textile fabrication and IRand thermal radiation-shielding experiments, we selected the PU-ATO (3) composite fiber because of its optimum mechanical properties and IR transmission.

As shown in Fig. 3g, h, the PU-ATO (3) composite fiberbased textile showed a hydrophobic property with water contact angles $\geq 130^{\circ}$ in all areas; accordingly, water droplets on the surface of the textile were not absorbed but easily rolled off. On the other hand, the PU-ATO (3) textile not subjected to hydrophobic treatment absorbed water droplets, which remained on the textile until natural drying. The PU-ATO composite fiber is hydrophobic due to the perfluoroalkyl chains of HDF-PA SAMs attached to its surface; the hydrophobicity of the fiber is essential for the fiber to maintain a certain level of IR- and thermal radiation-shielding capability. When the fiber is exposed to water, it absorbs water, and the absorbed water causes IR image distortion according to the absorption of the IR and thermal radiation. Accordingly, the pristine PU-ATO (3) composite fiber-based textile showed IR distortion in all areas where water was absorbed, whereas the hydrophobic PU-ATO (3) composite fiber-based textile could maintain stable IR- and thermal radiation-shielding properties because it was not wetted by water (Supplementary Figs S6, S7, Supplementary Information). Figure 3i shows the IRand thermal radiation-shielding properties after the removal of water droplets from hydrophobic and nonhydrophobic (untreated) PU-ATO (3) composite fiber-based textiles. After placing pristine and hydrophobic PU-ATO (3) composite fiber-based textiles, each with a size of $\sim 50 \mathrm{~mm}^{2}$, side by side on a hot plate heated to $40^{\circ} \mathrm{C}$, we observed the textiles with a thermal IR camera after $1 \mathrm{~min}$. The results indicated that the hydrophobic PU-ATO (3) composite fiber-based textile exhibits stable IR- and thermal radiationshielding properties, whereas the PU-ATO (3) composite fiber-based textile not subjected to hydrophobic treatment exhibits different IR and thermal radiation intensities depending on whether the textile is dry or wet. This confirms that IR and thermal radiation intensity could be distorted by water.

Figure 4 compares the IR- and thermal radiationshielding properties of the PU-ATO (3) textile when irradiated with thermal IR light in the high- and lowtemperature range. Figure 4a shows the optical and IR images of polyester, PU, and PU-ATO (3) composite 
A

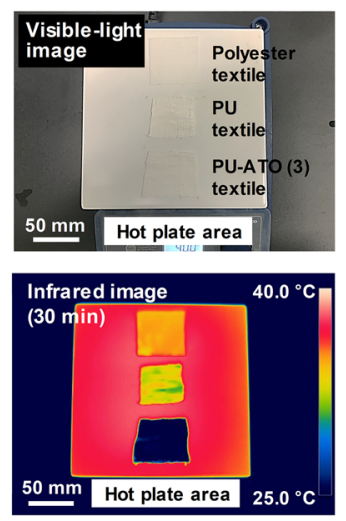

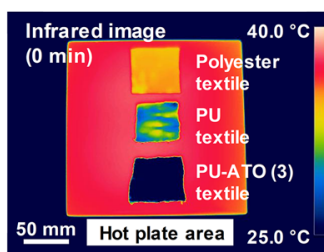
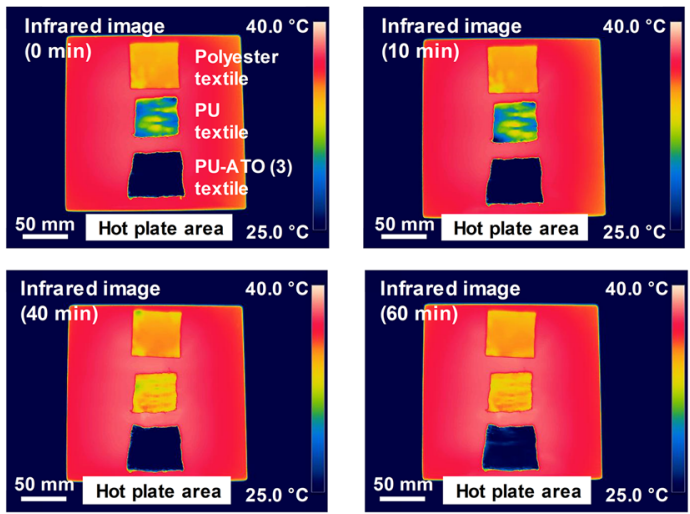

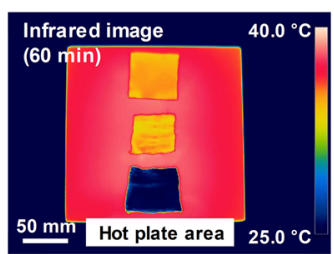

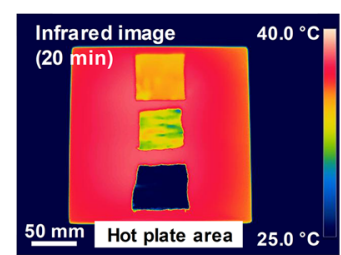

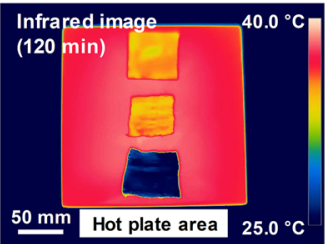

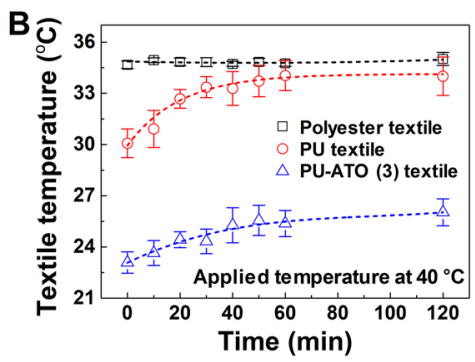
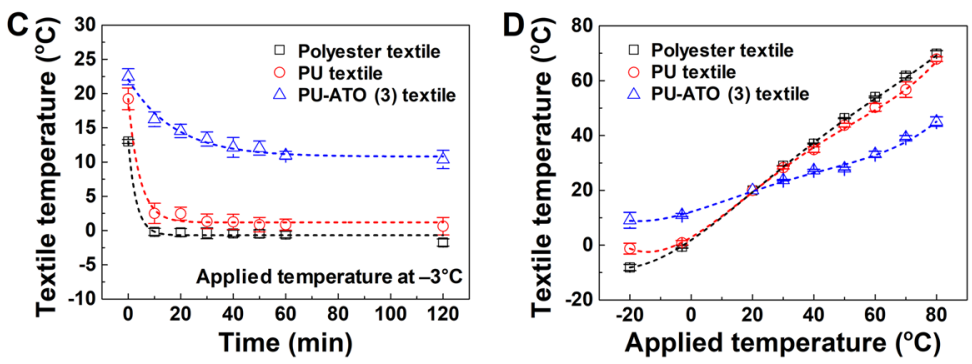

Fig. 4 Verification of the IR- and thermal radiation-shielding properties of the composite PU-ATO (3) textiles. a Visible-light images of polyester, PU, and PU-ATO (3) composite textiles placed on a hot plate heated to $40^{\circ} \mathrm{C}$ and IR images over time up to $120 \mathrm{~min}$. Trends in the temperature change of polyester, PU, and PU-ATO (3) composite textiles over time with the applied temperature condition of (b) $40^{\circ} \mathrm{C}$ and $(\mathbf{c})-3{ }^{\circ} \mathrm{C}$. d The temperatures of the polyester, PU, and PU-ATO (3) composite textiles were measured after 60 min under different applied temperature conditions (from -20 to $80^{\circ} \mathrm{C}$ ).

textiles placed on top of the hot plate, a thermal IR light source. Changes in the temperature of three types of textiles $\left(\sim 50 \mathrm{~mm}^{2}\right)$ placed $2 \mathrm{~mm}$ above the surface of the hot plate heated to $40^{\circ} \mathrm{C}$ were observed over a period of 120 min with a thermal IR camera. Note that the temperature at a distance $2 \mathrm{~mm}$ away from the $40^{\circ} \mathrm{C}$ hot plate was $\sim 36^{\circ} \mathrm{C}$. For each textile, the temperature from nine different points on the textile was measured, and the mean value with standard deviation is reported. The textiles of different materials placed on top of the hot plate showed different patterns of surface temperature over time. As the polyester textile has weak IR- and thermal radiation-shielding properties, its surface temperature reached $\sim 35.0^{\circ} \mathrm{C}$ immediately $(0 \mathrm{~min})$ after it was placed $2 \mathrm{~mm}$ from the surface of the hot plate at $40^{\circ} \mathrm{C}$, and the same temperature appeared even after $120 \mathrm{~min}$. Further, because of its inherent IR- and thermal radiation-shielding properties, the $\mathrm{PU}$ textile showed an initial surface temperature of $30.1^{\circ} \mathrm{C}$, which gradually increased over time to $32.7(20 \mathrm{~min})$ and $34.0^{\circ} \mathrm{C}(60 \mathrm{~min})$. As the surface temperature of the PU textile increased, color changes appeared in the IR image. On the other hand, owing to its strong IR- and thermal radiation-shielding properties, the PU-ATO (3) composite textile showed an initial surface temperature of $23.1^{\circ} \mathrm{C}$, which increased only slightly over time to $24.4(20 \mathrm{~min})$ and $25.4{ }^{\circ} \mathrm{C}(60 \mathrm{~min})$.
Figure $4 \mathrm{~b}$ shows the graphs of the surface temperature trend between 0 and $120 \mathrm{~min}$ of maintaining the polyester, PU, and PU-ATO (3) composite textiles at the applied temperature of $40^{\circ} \mathrm{C}$. The polyester textile showed almost the same temperature of $\sim 35^{\circ} \mathrm{C}$ between 0 and $120 \mathrm{~min}$. The PU textile showed an initial temperature of $30.1^{\circ} \mathrm{C}$, which increased sharply to a saturated value of $\sim 34.0^{\circ} \mathrm{C}$ after $60 \mathrm{~min}$. By contrast, the PU-ATO (3) textile initially showed a low surface temperature of $23.1^{\circ} \mathrm{C}$ and maintained a relatively low surface temperature throughout the experimental duration, gradually reaching $26.0^{\circ} \mathrm{C}$ after $120 \mathrm{~min}$. Figure $4 \mathrm{c}$ shows the graphs of the surface temperature trend between 0 and $120 \mathrm{~min}$ for the polyester, PU, and PU-ATO (3) composite textiles at the low-temperature condition with an applied temperature of $-3{ }^{\circ} \mathrm{C}$. The polyester and PU textiles showed initial surface temperatures of 13.0 and $19.2{ }^{\circ} \mathrm{C}$, respectively, dropping sharply to -0.2 and $2.5^{\circ} \mathrm{C}$ over $10 \mathrm{~min}$. After $10 \mathrm{~min}$, the surface temperature saturated, ultimately reaching surface temperatures of -1.7 (polyester) and $0.6^{\circ} \mathrm{C}(\mathrm{PU})$ after $120 \mathrm{~min}$. On the other hand, the PU-ATO (3) composite textile showed a surface temperature of $22.5^{\circ} \mathrm{C}$ at $0 \mathrm{~min}$, followed by modest decreases to 9.0 and $8.3^{\circ} \mathrm{C}$ after 60 and $120 \mathrm{~min}$, respectively (Supplementary Fig. S8, Supplementary Information). In addition, under the harsh low-temperature 
A
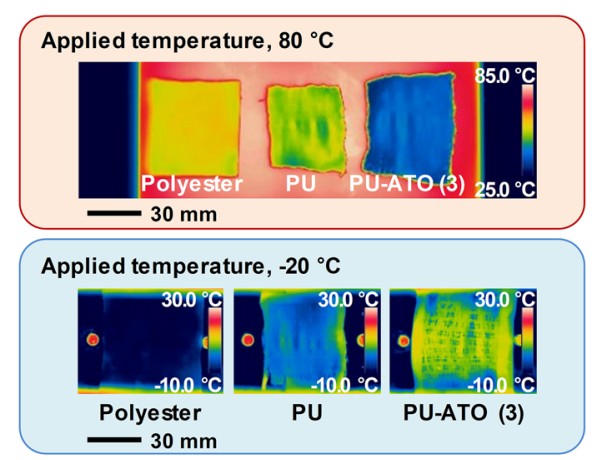

C

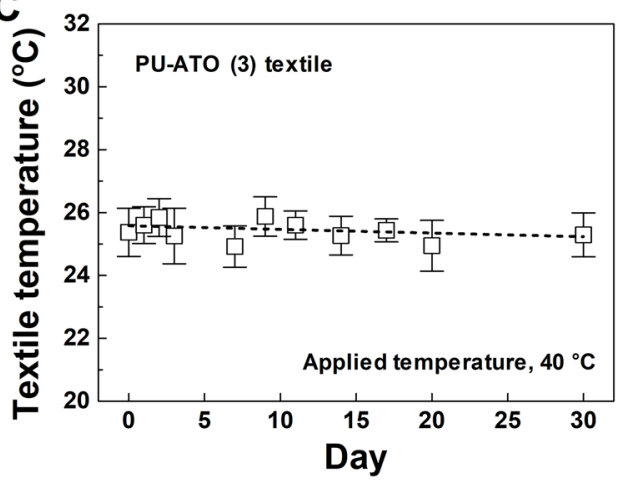

B

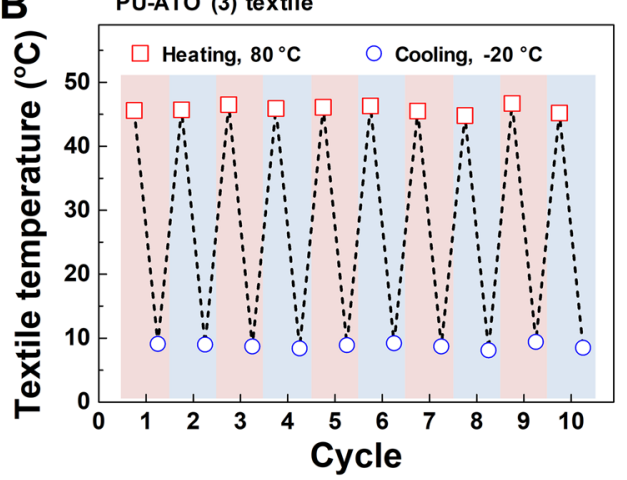

D
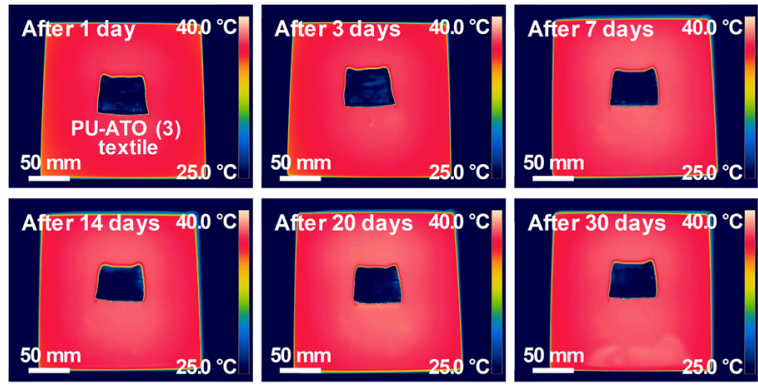

Fig. 5 Repeated assessment of the IR- and thermal radiation-shielding properties of the PU-ATO (3) composite textile according to the changes in temperature and time. a IR images of polyester, PU, and PU-ATO (3) composite textiles after 60 min under applied temperatures of +80 and $-20^{\circ} \mathrm{C}$. b Surface temperature of the PU-ATO (3) composite textile subjected to repeated heating $\left(+80^{\circ} \mathrm{C}\right)$ and cooling $\left(-20^{\circ} \mathrm{C}\right)$ cycles. c Graph of the surface temperature and $\mathbf{d}$ representative IR images of the PU-ATO (3) composite textile after the application of a temperature of $40^{\circ} \mathrm{C}$ for $8 \mathrm{~h}$ per day for a total of 30 days.

condition of $-20^{\circ} \mathrm{C}$, the change in the temperature of the PU-ATO (3) composite textile was modest in comparison with those of the polyester and PU textiles (Supplementary Fig. S9, Supplementary Information). Thus, the results indicated that the IR- and thermal radiation-shielding properties of the PU-ATO (3) textile function effectively under both high- and low-temperature conditions.

Figure $4 \mathrm{~d}$ shows the surface temperature reached by the polyester, PU, and PU-ATO (3) composite textiles after 60 min under varying applied temperature conditions, including room temperature $\left(20^{\circ} \mathrm{C}\right)$ as the reference and $-20,-3,+30,+40,+50,+60,+70$, and $+80^{\circ} \mathrm{C}$. The polyester and PU textiles attained a surface temperature that was as high as $\sim 90 \%$ of the applied temperature. In contrast, the PU-ATO (3) composite textile showed very small changes in the surface temperature, despite the significant changes in the applied temperatures. Under the harshest temperature condition of $80^{\circ} \mathrm{C}$, the polyester and PU textiles showed surface temperatures of 69.9 and $67.9^{\circ} \mathrm{C}$, respectively, with differences of 10.1 (polyester) and $12.1{ }^{\circ} \mathrm{C}$ (PU) compared with the applied temperature $\left(80^{\circ} \mathrm{C}\right)$. Under the $-20^{\circ} \mathrm{C}$ condition, the polyester and PU textiles showed surface temperatures of -8.1 and $-1.3{ }^{\circ} \mathrm{C}$, respectively, with differences of -11.9 (polyester) and $-18.7^{\circ} \mathrm{C}$ (PU) compared with the applied temperature $\left(-20^{\circ} \mathrm{C}\right)$. In contrast, the PU-ATO (3) composite textile with strong IR- and thermal radiation-shielding properties showed surface temperatures of $45.1^{\circ} \mathrm{C}$ and $9.1^{\circ} \mathrm{C}$, respectively, under $80^{\circ} \mathrm{C}$ and $-20^{\circ} \mathrm{C}$ conditions. The results indicate that despite the applied temperature being changed by $100^{\circ} \mathrm{C}\left(-20\right.$ to $\left.+80^{\circ} \mathrm{C}\right)$, the surface temperature of the PU-ATO (3) composite textile changed by only $36.0^{\circ} \mathrm{C}$, which is only $\sim 1 / 3$ of the actual change in applied temperature. For reference, under the condition of $30-40^{\circ} \mathrm{C}$, which is similar to human body temperature, the surface temperature of the PU-ATO (3) composite textile was $24-27^{\circ} \mathrm{C}$. This temperature is lower than that of polyester $\left(29-37^{\circ} \mathrm{C}\right)$ and $\mathrm{PU}\left(28-35^{\circ} \mathrm{C}\right)$, indicating the more effective shielding of IR and thermal radiation by the PU-ATO (3) composite textile.

To be used as a practical wearable textile, the textile must maintain its IR- and thermal radiation-shielding properties in an environment with a constantly changing temperature. For this, the reliability of IR- and thermal radiation- 
shielding properties must be verified by repeatedly applying high- and low-temperature conditions or by considering its performance during long-term exposure under a single temperature condition. Figure $5 \mathrm{a}$ shows the IR images of polyester-based, PU-based, and PU-ATO (3) compositebased textiles after exposure for $60 \mathrm{~min}$ to temperatures of 80 and $-20^{\circ} \mathrm{C}$. Note that a hot plate was used to apply the high temperature of $80^{\circ} \mathrm{C}$, and a Peltier module was used to apply the low temperature of $-20^{\circ} \mathrm{C}$. In the IR images, the PU-ATO (3) composite textile shows a lower temperature of $\sim 45^{\circ} \mathrm{C}$ under the high-temperature condition of $80^{\circ} \mathrm{C}$. In contrast, it shows a temperature of $\sim 9^{\circ} \mathrm{C}$ under the lowtemperature condition of $-20^{\circ} \mathrm{C}$, which is higher than that of the polyester and PU textiles. Figure $5 \mathrm{~b}$ shows the results of repeatedly exposing the PU-ATO (3) composite textile to high $\left(+80^{\circ} \mathrm{C}\right)$ and low $\left(-20^{\circ} \mathrm{C}\right)$ temperatures. The surface temperatures were measured after $60 \mathrm{~min}$ at each of the high- and low-temperature conditions, with the cycle repeated ten times. The surface temperature of the PU-ATO (3) composite textile remained steady at $45.8 \pm$ $0.6^{\circ} \mathrm{C}$ and $8.8 \pm 0.4{ }^{\circ} \mathrm{C}$ after repeated exposure to high $\left(+80^{\circ} \mathrm{C}\right)$ and low $\left(-20^{\circ} \mathrm{C}\right)$ temperatures, respectively. These findings confirm that the IR- and thermal radiationshielding properties of the PU-ATO (3) composite textile could be maintained even when repeatedly exposed to highand low-temperature conditions. The radiation absorbed by the surface of the object is converted into thermal energy through the vibration of the molecules, thereby increasing the surface temperature of the object and emitting radiant heat corresponding to the fourth power of the surface temperature through infrared rays. The heat radiation energy, referred to as thermal infrared rays, can thus be controlled according to the temperature and wavelength. As such, the infrared rays have a deep correlation with heat and cannot be explained separately from heat. Therefore, the PU-ATO (3) composite textiles with low heat-transfer capability are able to extensively block IR radiation. Figure $5 \mathrm{c}$ shows the continuous IR- and thermal radiationshielding properties of the PU-ATO (3) composite textile over time. The applied temperature was set to $40^{\circ} \mathrm{C}$ in consideration of the typical environment encountered. The surface temperature of the textile was measured with application of a temperature of $40^{\circ} \mathrm{C}$ for $8 \mathrm{~h}$ per day for a total of 30 days. The surface temperature of the textile was maintained at $\sim 25^{\circ} \mathrm{C}$, even over a long duration. Furthermore, Fig. $5 \mathrm{~d}$ shows the IR- and thermal radiation-shielding properties of the PU-ATO (3) composite textile over different durations $(1,3,7,14,20$, and 30 days). As shown in the IR images, the IR- and thermal radiation-shielding properties were maintained over time.

\section{Conclusion}

In this study, we fabricated a PU-ATO composite fiber and used it to weave wearable textiles with IR- and thermal radiation-shielding properties. The ATO sol prepared by a typical sol-gel method showed changes in its IR transmission property according to the process conditions, such as the aging time and concentration. Moreover, a PU-ATO composite fiber consisting of an ATO sol with IR- and thermal radiation-shielding properties evenly embedded in a PU matrix was fabricated, and the mechanical, chemical, and optical properties of the obtained fabric were analyzed. Based on the findings, the optimal concentration and aging time of the ATO sol mixed with PU for a wearable textile were identified. The PU-ATO (3) composite fiber used to fabricate IR- and thermal radiation-shielding textiles had a tensile strength of $3.90 \mathrm{MPa}$ and strain of $335.7 \%$; the ATR-FTIR study confirmed the IR transmission to be $\leq 2 \%$. The IR- and thermal radiation-shielding textile made from optimized PU-ATO (3) composite fiber showed excellent IR- and thermal radiation-shielding properties when observed with a thermal imaging camera applied to heating and cooling sources $\left(-20\right.$ to $\left.80^{\circ} \mathrm{C}\right)$, such as a human body, hot plate, or Peltier cooling plate. Moreover, a hydrophobic treatment was performed on the fabricated PU-ATO composite fiber to prevent the distortion of the IR- and thermal radiation-shielding properties due to the absorption of water. To assess the reliability of the PU-ATO composite fiber, it was exposed repeatedly (ten times) to extreme temperature conditions of $80^{\circ} \mathrm{C}$ and $-20^{\circ} \mathrm{C}$ and subjected to long-term exposure at $40^{\circ} \mathrm{C}$ for 30 days. The results confirmed that the fiber's IR- and thermal radiationshielding capabilities can be stably maintained under those conditions. With the continuing development of stealth technology used to conceal IR signals originating from objects, the PU-ATO composite fiber is expected to lead to a new market surrounding wearable IR stealth products; such products can advantageously be fabricated into a wearable form, which is not feasible with conventional thin films or paint coating methods.

\section{Acknowledgements \\ This work was supported by National Research Foundation of Korea (NRF) grants funded by the Korean government (MSIP) (2017M3C1A9069593, 2017M3A7B4025166, 2017R1D1A1B04030415, 2019R1C1C1010688, 2018M3A7B4070987, and 2019R1A2(2010614).}

\section{Author details \\ 'Department of Physics, Kyonggi University, Suwon, Gyeonggi-do 16227, Republic of Korea. ${ }^{2}$ Department of Physics and Oxide Research Center, Hankuk University of Foreign Studies, Yongin-si, Gyeonggi-do 17579, Republic of Korea. ${ }^{3}$ Advanced Institutes of Convergence Technology, Seoul National University, Suwon-si, Gyeonggi-do 16229, Republic of Korea}

Conflict of interest

The authors declare that they have no conflict of interest.

\section{Publisher's note}

Springer Nature remains neutral with regard to jurisdictional claims in published maps and institutional affiliations. 
Supplementary information is available for this paper at https://doi.org/ 10.1038/s41427-020-0213-z.

Received: 17 November 2019 Revised: 5 February 2020 Accepted: 1 March 2020.

Published online: 24 April 2020

\section{References}

1. Balci, O., Polat, E. O., Kakenov, N. \& Kocabas, C. Graphene-enabled electrically switchable radar-absorbing surfaces. Nat. Commun. 6, 6628 (2015).

2. Shelby, R. A., Smith, D. R. \& Schultz, S. Experimental verification of a negative index of refraction. Science 292, 77-79 (2001).

3. Jannasch, A., Demirörs, A. F., van Oostrum, P. D. J., van Blaaderen, A. \& Schäffer, E. Nanonewton optical force trap employing anti-reflection coated, highrefractive-index titania microspheres. Nat. Photonics 6, 469 (2012).

4. Diao, Z., Kraus, M., Brunner, R., Dirks, J. H. \& Spatz, J. P. Nanostructured stealth surfaces for visible and near-infrared light. Nano Lett. 16, 6610-6616 (2016).

5. Wen, X.-Y. et al. Nanocomposite hydrogels with optic-sonic transparency and hydroacoustic-sensitive conductivity for potential antiscouting sonar. ACS Appl. Mater. Interfaces 11, 20386-20393 (2019).

6. Zigoneanu, L., Popa, B.-I. \& Cummer, S. A. Three-dimensional broadband omnidirectional acoustic ground cloak. Nat. Mater. 13, 352 (2014).

7. Xu, C., Stiubianu, G. T. \& Gorodetsky, A. A. Adaptive infrared-reflecting systems inspired by cephalopods. Science 359, 1495-1500 (2018).

8. Phan, L. et al. Reconfigurable infrared camouflage coatings from a cephalopod protein. Adv. Mater. 25, 5621-5625 (2013).

9. Qu, Y. et al. Thermal camouflage based on the phase-changing material GST. Light:: Sci. Appl. 7, 26 (2018).

10. Salihoglu, O. et al. Graphene-based adaptive thermal camouflage. Nano Lett. 18, 4541-4548 (2018)

11. Zhang, W., Xu, G., Ding, R., Duan, K. \& Qiao, J. Nacre biomimetic design-a possible approach to prepare low infrared emissivity composite coatings. Mater. Sci. Eng.: C. 33, 99-102 (2013).

12. Zabetakis, D., Dinderman, M. \& Schoen, P. Metal-coated cellulose fibers for use in composites applicable to microwave technology. Adv. Mater. 17, 734-738 (2005).

13. Yu, H., Xu, G., Shen, X., Yan, X. \& Cheng, C. Low infrared emissivity of polyurethane/Cu composite coatings. Appl. Surf. Sci. 255, 6077-6081 (2009).

14. Yang, C. C., Gung, Y. J., Hung, W. C., Ting, T. H. \& Wu, K. H. Infrared and microwave absorbing properties of $\mathrm{BaTiO}_{3} /$ polyaniline and $\mathrm{BaFe}_{12} \mathrm{O}_{19} /$ polyaniline composites. Compos. Sci. Technol. 70, 466-471 (2010).

15. Biswas, P. K. et al. Effects of tin on IR reflectivity, thermal emissivity, Hall mobility and plasma wavelength of sol-gel indium tin oxide films on glass. Mater. Lett. 57, 2326-2332 (2003).

16. Luo, H. et al. An ultra-thin colored textile with simultaneous solar and passive heating abilities. Nano Energy 65, 103998 (2019).

17. Cai, L. et al. Temperature regulation in colored infrared-transparent polyethylene textiles. Joule 3, 1478-1486 (2019).

18. Yuan, L., Weng, X. \& Deng, L. Influence of binder viscosity on the control of infrared emissivity in low emissivity coating. Infrared Phys. Technol. 56, 25-29 (2013).

19. Fang, F., Kennedy, J., Carder, D., Futter, J. \& Rubanov, S. Investigations of near infrared reflective behaviour of $\mathrm{TiO}_{2}$ nanopowders synthesized by arc discharge. Optical Mater. 36, 1260-1265 (2014).

20. Liu, J., Lu, Y., Liu, J., Yang, X. \& Yu, X. Investigation of near infrared reflectance by tuning the shape of $\mathrm{SnO}_{2}$ nanoparticles. J. Alloy. Compd. 496, 261-264 (2010).

21. $\mathrm{Xu}, \mathrm{J}$. M. et al. Influence of Sb doping on the structural and optical properties of tin oxide nanocrystals. CrystEngComm 15, 3296-3300 (2013).

22. Jung, D.-W. \& Park, D.-W. Synthesis of nano-sized antimony-doped tin oxide (ATO) particles using a DC arc plasma jet. Appl. Surf. Sci. 255, 5409-5413 (2009).

23. Lili, L., Liming, M. \& Xuechen, D. Solvothermal synthesis and characterization of $\mathrm{Sb}$-doped $\mathrm{SnO}_{2}$ nanoparticles used as transparent conductive films. Mater. Res. Bull. 41, 541-546 (2006).

24. Senthilkumar, V., Vickraman, P., Jayachandran, M. \& Sanjeeviraja, C. Structural and electrical studies of nano structured $\mathrm{Sn}_{1-x} \mathrm{Sb}_{x} \mathrm{O}_{2}(x=0.0,1,2.5,4.5$ and 7 at\%) prepared by co-precipitation method. J. Mater. Sci.: Mater. Electron. 21 343-348 (2010).

25. Jin, X., Xiao, C. F., An, S. L. \& Jia, G. X. Preparation of electrically conductive fibres by new surface coating method. Mater. Sci. Technol. 22, 1469-1475 (2006).

26. Chen, X., Li, C., Shao, W. \& He, J. Preparation and properties of poly(ethylene terephthalate)/ATO nanocomposites. J. Appl. Polym. Sci. 105, 2783-2790 (2007).

27. Pan, W., He, X. \& Chen, Y. Preparation and characterization of polyacrylonitrile/ antimony doped tin oxide composite nanofibers by electrospinning method. Optoelectron. Adv. Mater., Rapid Commun. 4, 390-394 (2010).

28. Wang, Y., Brezesinski, T., Antonietti, M. \& Smarsly, B. Ordered mesoporous Sb-, $\mathrm{Nb}$-, and Ta-Doped $\mathrm{SnO}_{2}$ Thin films with adjustable doping levels and high electrical conductivity. ACS Nano 3, 1373-1378 (2009).

29. Lekshmy, S. S., Daniel, G. P. \& Joy, K. Microstructure and physical properties of sol gel derived SnO2:Sb thin films for optoelectronic applications. Appl. Surf. Sci. 274, 95-100 (2013).

30. Huang, $\mathrm{H}_{\text {., Ng}}$, M., Wu, Y. \& Kong, L. Solvothermal synthesis of $\mathrm{Sb}: \mathrm{SnO}_{2}$ nanoparticles and IR shielding coating for smart window. Mater. Des. 88, 384-389 (2015).

31. Zhang, D., Deng, Z., Zhang, J. \& Chen, L. Microstructure and electrical properties of antimony-doped tin oxide thin film deposited by sol-gel process. Mater. Chem. Phys. 98, 353-357 (2006).

32. Terrier, C., Chatelon, J. P., Berjoan, R. \& Roger, J. A. Sb-doped $\mathrm{SnO}_{2}$ transparent conducting oxide from the sol-gel dip-coating technique. Thin Solid Films $\mathbf{2 6 3}$, 37-41 (1995).

33. Runnerstrom, E. L., Llordés, A., Lounis, S. D. \& Milliron, D. J. Nanostructured electrochromic smart windows: traditional materials and NIR-selective plasmonic nanocrystals. Chem. Commun. 50, 10555-10572 (2014).

34. Peng, L., Chen, W., Su, B., Yu, A. \& Jiang, X. Cs $W_{3} O_{3}$ nanosheet-coated cotton fabric with multiple functions: UV/NIR shielding and full-spectrum-responsive self-cleaning. Appl. Surf. Sci. 475, 325-333 (2019).

35. Peng, $\mathrm{L}$. et al. IR protection property and color performance of $\mathrm{TiO}_{2} / \mathrm{Cu} /$ $\mathrm{TiO}_{2}$ coated polyester fabrics. J. Mater. Sci.: Mater. Electron. 29. 16188-16198 (2018).

36. Peng, L., Chen, W., Yu, A. \& Jiang, X. Near-infrared shielding and far-infrared emission textiles coated by self-assembly $\mathrm{Cs}_{0.32} \mathrm{WO}_{3}$ nanosheets. Int. J. Chem. Eng. Appl. 10, 168-174 (2019).

37. Jiang, S. et al. Preparation and characterization of shielding textiles to prevent infrared penetration with Ag thin films. J. Mater. Sci.: Mater. Electron. 28, 3542-3547 (2017).

38. Shang, S., Wang, Y., Chiu, K.I \& Jiang, S. Solar heat shielding performance of potassium titanate whisker coated polypropylene fabric based on a bionic method. Compos. Part B: Eng. 177, 107408 (2019).

39. Li, Y., Wang, J., Feng, B., Duan, K. \& Weng, J. Synthesis and characterization of antimony-doped tin oxide (ATO) nanoparticles with high conductivity using a facile ammonia-diffusion co-precipitation method. J. Alloy. Compd. 634, 37-42 (2015).

40. Li, J., Yang, D. \& Zhu, X. Effects of aging time and annealing temperature on structural and optical properties of sol-gel ZnO thin films. AIP Adv. 7, 065213 (2017).

41. Bretos, I., Jiménez, R., Ricote, J. \& Calzada, M. L. Low-temperature crystallization of solution-derived metal oxide thin films assisted by chemical processes. Chem. Soc. Rev. 47, 291-308 (2018)

42. Hotchkiss, P. J. et al. The modification of indium tin oxide with phosphonic acids: mechanism of binding, tuning of surface properties, and potential for use in organic electronic applications. Acc. Chem. Res. 45, 337-346 (2012).

43. Magnago, R. F. et al. Investigating the influence of conduit residues on polyurethane plates. Polímeros 27, 141-150 (2017).

44. Venkatesan, H., Hu, J. \& Chen, J. Bioinspired fabrication of polyurethane/ regenerated silk fibroin composite fibres with tubuliform silk-like flat stress-strain behaviour. Polymers 10, 333 (2018).

45. Seyedin, M. Z., Razal, J. M., Innis, P. C. \& Wallace, G. G. Strain-responsive polyurethane/PEDOT:PSS elastomeric composite fibers with high electrical conductivity. Adv. Funct. Mater. 24, 2957-2966 (2014).

46. Pedicini, A. \& Farris, R. J. Mechanical behavior of electrospun polyurethane Polymer 44, 6857-6862 (2003). 